\title{
Congenital dyserythropoietic anemia associated to a GATA1mutation aggravated by pyruvate kinase deficiency
}

\author{
Janet Pereira ${ }^{1}$, Celeste Bento ${ }^{1}$, Licinio Manco ${ }^{1}$, Ataulfo Gonzalez ${ }^{2}$, Jose Vagace ${ }^{3}$, \\ Maria Letícia Ribeiro ${ }^{1}$ \\ ${ }^{1}$ Serviço de Hematologia Clínica, Hospital Pediátrico, Centro Hospitalar e \\ Universitário de Coimbra, Avenida Afonso Romão, 3000-602 Coimbra, Portugal \\ ${ }^{2}$ Departamento de Hematología, Hospital Clínico San Carlos, Madrid, Spain \\ ${ }^{3}$ Departamento de Hematología Pediátrica, Hospital Materno Infantil, Badajoz, Spain
}

\section{Dear Editor,}

A 12-year-old Spanish male was referred to our department to elucidate the etiology of a congenital macrocytic anemia (MCV $104 \mathrm{fL}$; Hb $9.0 \mathrm{~g} / \mathrm{dL}$ ) with dyserythropoiesis, needing blood transfusions during the first 4 months of life, and mild thrombocytopenia $(73 \times 109 / \mathrm{L})$ with large platelets. At the age of 3 months, he presented: Hb $5.9 \mathrm{~g} / \mathrm{dL}$, reticulocytes $105 \times 1012 / \mathrm{L}$, peripheral blood smear with anisocytosis, poikilocytosis, and basophilic stippling. He has a low PK activity ( $45 \%$ of normal). The bone marrow was suggestive of congenital dyserythropoietic anemia (CDA), with erythroid hyperplasia and dyserythropoiesis and orthochromatic erythroblasts showing an irregular nuclear contour and bi- or multinucleated erythroblasts; electronic microscopy identified vacuoles in the cytoplasm of erythroblasts.

CDAs are rare forms of bone marrow failure syndromes characterized by ineffective erythropoiesis $[1,2]$. There are three classical forms of CDA presentation due to mutations in CDANI, C15orf41, SEC23B, and KIF23 [3-5] and rarer forms associated with pathological variants in KLF1 and GATA1. GATA1 variants are associated with deregulation of erythroid and megakaryocytic lineages differentiation [6-8].

We studied the patient and available family members (Fig. 1), results are summarized in Table 1. Sequence analysis of CDANI, SEC23B, C15ORF41, KLF1, HBB, HBA was normal, in PKLR, we found a new pathological variant c.1284delA (Glu429Argfs*19) in the heterozygous state. His mother and sister were also heterozygous for PKLR c.1284delA. The heterogeneity of family's data affecting both erythroid and megakaryocytic lines prompted us to perform sequencing analysis of GATA1. An A to G transition (c.866 A > G) was identified in the propositus in hemizygous state. Interestingly, PK activity was also decreased in the GATA1 hemizygous relative studied (Table 1-III-2). This pedigree illustrates the difference of the hematological manifestations among the propositus, carrier of mutations at the GATA1 and PKLR, and the other family males, presenting only the GATA1 mutation.

This novel GATA1 mutation results in the substitution of histidine for arginine (p.His289Arg) in the C-terminal zinc finger. This residue is conserved across GATA1 orthologs of various species, and bioinformatics analysis classifies the variant as pathological. The mutation was not detected in 100 normal chromosomes and was published by us in the GenBank (Accession Number KC733811).

This is the first report of a CDA associated with a mutation in the GATA1 in a region coding for the Cterminal zinc finger domain of GATA1 protein, necessary for DNA 
binding [9]. GATA1 is an important transcription factor for hematopoiesis regulation, in particular for the erythroid and megakaryocyte lineages. Mutations affecting the $\mathrm{C}$ terminal zinc finger domain are probably not as damaging as those affecting the $\mathrm{N}$ terminal, which would account for the milder phenotypes of hemizygous males, with mild macrocytic anemia. To explain the more severe phenotype of the propositus comparatively to his affected male cousins, we hypothesize this is due to the coinheritance of the mutated PKLR allele. In fact, the lower than expected PK activity may reflect the association of the PKLR mutated allele with a decreased PKLR expression due to the GATA1 mutation. This hypothesis is supported by the fact that the PK activity is also decreased in the GATA1 hemizygous (III-2). As previously reported, mutations in the PKLR gene GATA motifs, required for the R-PK promoter activity, disable the binding of the GATA1, decreasing the normal PKLR gene expression [10]. This is the first description how a heterozygous PK deficiency, otherwise harmless, can lead to clinically significant anemia. Inherited GATA1 mutations are rare, presenting with a large range of clinical manifestations dependent of the type and localization of the mutation (8).

\section{Acknowledgments}

We thank the patient and family who consented to this study. We are also grateful to Elizabete Cunha, Luis Relvas, Ana Catarina Oliveira, and Helena Almeida for the assistance in the laboratory work and to Joana Azevedo for the comments on the manuscript. This study was supported in part by Forum Hematológico de Coimbra, Portugal.

\section{Conflict of interest}

The authors declare that they have no conflict of interest.

Ethical statements Informed consent was obtained from all individual participants included in the study. All procedures were in accordance with the Helsinki Declaration of 1975 , as revised in 2008.

\section{References}

1. Wickramasinghe SN, Wood WG (2005) Advances in the understanding of the congenital dyserythropoietic anaemias. Br J Haematol 131:431-446

2. Iolascon A, Esposito MR, Russo R (2012) Clinical aspects and pathogenesis of congenital dyserythropoietic anemias: from morphology to molecular approach. Haematologica 97(12):1786-1794

3. Dgany O, Avidan N, Delaunay J, Krasnov T, Shalmon L, Shalev H, Eidelitz-Markus T, Kapelushnik J, Cattan D, Pariente A, Tulliez M, Crétien A, Schischmanoff PO, Iolascon A, Fibach E, Koren A, Rössler J, Le Merrer M, Yaniv I, Zaizov R, Ben-Asher E, Olender T, Lancet D, Beckmann JS, Tamary H (2002) Congenital dyserythropoietic anemia type I is caused by mutations in codanin-1. Am J Hum Genet 71:1467-1474

4. Bianchi P, Fermo E, Vercellati C, Boschetti C, Barcellini W, Iurlo A, Marcello AP, Righetti PG, Zanella A (2009) Congenital dyserythropoietic anemia type II (CDA II) is caused by mutations in the SEC23B gene. Hum Mutat 30:1292-1298 
5. Liljeholm M, Irvine AF, Vikberg AL, Norberg A, Month S, Sandström H, Wahlin A, Mishima M, Golovleva I (2013) Congenital dyserythropoietic anemia type III (CDA III) is caused by a mutation in kinesin family member, KIF23. Blood 121(23): 4791-4799

6. Arnaud L, Saison C, Helias V, Lucien N, Steschenko D, Giarratana MC, Prehu C, Foliguet B, Montout L, de Brevern AG, Francina A, Ripoche P, Fenneteau O, Da Costa L, Peyrard T, Coghlan G, Illum N, Birgens H, Tamary H, Iolascon A, Delaunay J, Tchernia G, Cartron JP (2010) A dominant mutation in the gene encoding the erythroid transcription factor KLF1 causes a congenital dyserythropoietic anemia. Am J Hum Genet 87:721-727

7. Nichols KE, Crispino JD, Poncz M, White JG, Orkin SH, Maris JM, Weiss MJ (2000) Familial dyserythropoietic anaemia and thrombocytopenia due to an inherited mutation in GATA1. Nat Genet 24:266-270

8. Ciovacco WA, Raskind WH, Kacena MA (2008) Human phenotypes associated with GATA-1 mutations. Gene 427(1-2):1-6

9. Imanishi M, Imamura C, Higashi C, Yan W, Negi S, Futaki S, Sugiura Y (2010) Zinc finger-zinc finger interaction between the transcription factors, GATA-1 and Sp1. Biochem Biophys Res Commun 400(4):625-630

10. Manco L, Ribeiro ML, Máximo V, Almeida H, Costa A, Freitas O, Barbot J, Abade A, Tamagnini G (2000) A new PKLR gene mutation in the R-type promoter region affects the gene transcription causing pyruvate kinase deficiency. Br J Haematol 110:993-997.

Figure. 1 Mutational analysis of the GATA1. A- Pedigree of the affected family. Black squares indicate hemizygous males and dotted circles, heterozygous females.

Underlined numbers indicate the individuals studied. The propositus is indicated by an arrow. B- DNA sequencing analysis of the exon 5 of the GATA1 gene showing an unaffected male (III-15, father), heterozygous female (III-14, mother), and affected male (IV-5, propositus) for the c.866 A > G transition (indicated by arrows). 


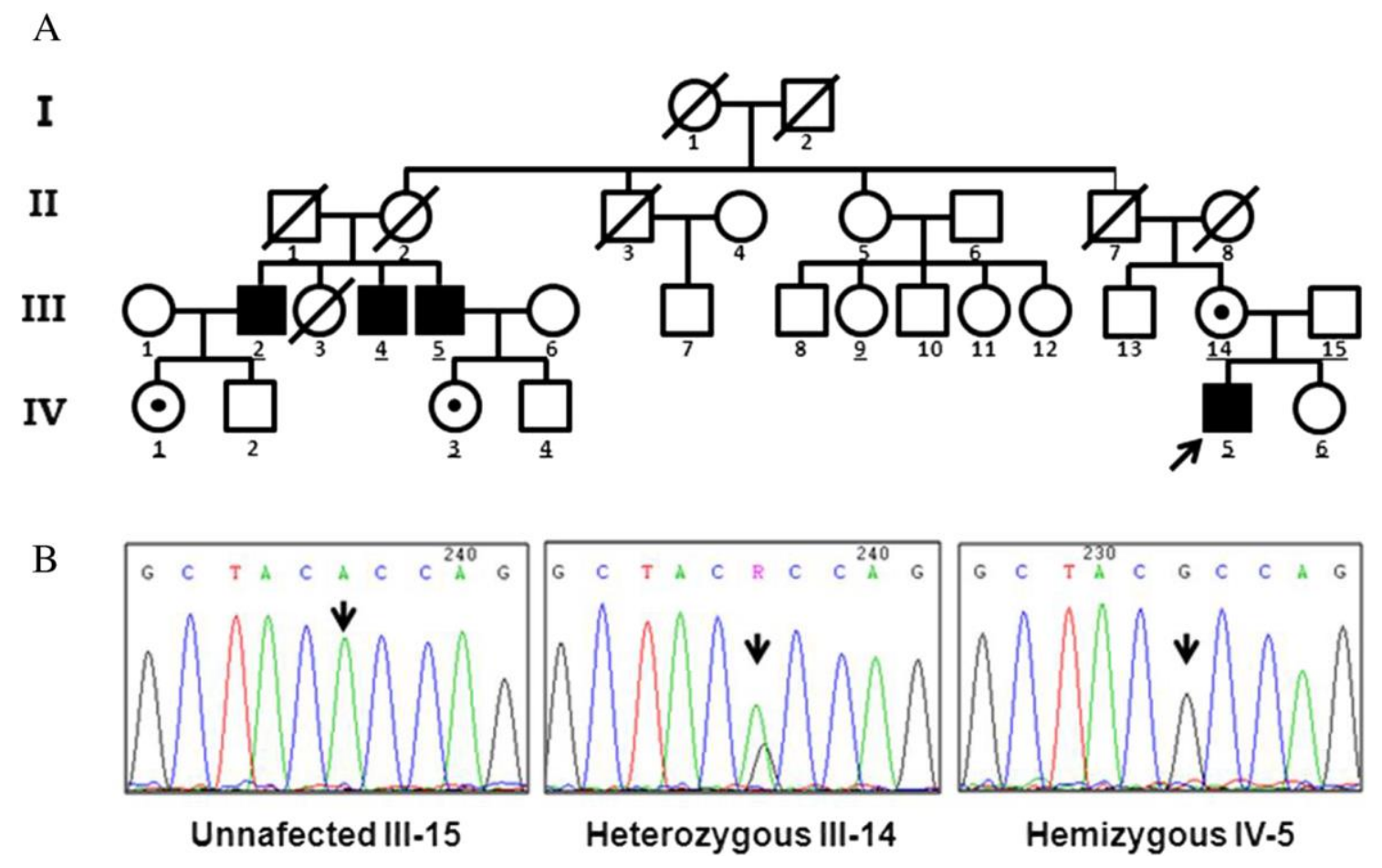

Table 1 - Hematological parameters of family members.

\begin{tabular}{|c|c|c|c|c|c|c|c|}
\hline & \multicolumn{4}{|l|}{ Affected males } & \multicolumn{3}{|l|}{ Carrier females } \\
\hline & IV-5 & III-2 & III-4 & III-5 & III-14 & IV-1 & IV-3 \\
\hline Age (year) & 12 & 56 & 62 & 54 & 43 & 30 & 28 \\
\hline $\mathrm{Hb}(\mathrm{g} / \mathrm{dL})\left(\mathrm{N} 13-17.5\left(\mathrm{O}^{-1}\right) 12-16(\mathrm{P})\right)$ & 10.3 & 14.5 & 13 & 13.8 & 13 & 12.9 & 14.1 \\
\hline MCV (fL) (N 80-100) & 104 & 102.5 & 116 & 107 & 96.5 & 96 & 102.3 \\
\hline MCH (pg) (N 27-33) & 36 & 34.2 & 40 & 36 & 33.2 & 32.6 & 33.9 \\
\hline MCHC (g/dL) (N 13-17.5) & 34.6 & 33.3 & 34.4 & 33.7 & 34.4 & 34 & 33.1 \\
\hline RDW (\%) (N 12-14) & 15 & 14.5 & 16.9 & 16.2 & 11 & 13.7 & 14.4 \\
\hline Reticulocytes $\left(\times 10^{12} / \mathrm{L}\right)(\mathrm{N} 50-100)$ & 149 & 77.4 & 88 & 91.5 & 58 & 64 & 16 \\
\hline Leukocytes $\left(\times 10^{3} / \mathrm{mm}^{3}\right)(\mathrm{N} 4-10)$ & 5 & 6.2 & 10.5 & 8 & 6.33 & 3.7 & 5.7 \\
\hline Platelets $\left(\times 10^{3} / \mathrm{mm}^{3}\right)(\mathrm{N} 150-400)$ & 73 & 129 & 208 & 185 & 243 & 173 & 170 \\
\hline MPV (fL) (N 8.2-9.7) & 10 & 10.6 & 8.4 & 11 & 7.5 & 9.6 & 9.1 \\
\hline PK activity (\% of N) & 45 & 69 & NA & NA & 62 & NA & NA \\
\hline PKLR c.1284delA mutation & Heterozygous & Normal & Normal & Normal & Heterozygous & Normal & Normal \\
\hline GATA-1 c. 866 A > G mutation & Hemizygous & & & & Heterozygous & & \\
\hline
\end{tabular}

NA not available 